\title{
Recovery of metals from waste printed circuit boards by supercritical water pre-treatment combined with acid leaching process
}

\author{
Fu-Rong Xiu ${ }^{\text {a,c,* }}$, Yingying Qi $^{\text {a }}$, Fu-Shen Zhang ${ }^{\mathrm{b}}$ \\ ${ }^{a}$ Department of Environment and Equipment Engineering, Fujian University of Technology, Fuzhou 350108, People's Republic of China \\ ${ }^{\mathrm{b}}$ Research Center for Eco-Environmental Sciences, Chinese Academy of Sciences, Beijing 100085, People's Republic of China \\ ${ }^{\mathrm{c}}$ Key Laboratory of Solid Waste Treatment and Recycle (SWUST), Ministry of Education, Mianyang 621010, People's Republic of China
}

\section{A R T I C L E I N F O}

Article history:

Received 29 October 2012

Accepted 19 January 2013

Available online 7 March 2013

\section{Keywords:}

Waste printed circuit board

Metal

Leaching

Supercritical water

\begin{abstract}
A B S T R A C T
Waste printed circuit boards (PCBs) contain a large number of metals such as $\mathrm{Cu}, \mathrm{Sn}, \mathrm{Pb}, \mathrm{Cd}, \mathrm{Cr}, \mathrm{Zn}$, and $\mathrm{Mn}$. In this work, an efficient and environmentally friendly process for metals recovery from waste PCBs by supercritical water (SCW) pre-treatment combined with acid leaching was developed. In the proposed process, waste PCBs were pre-treated by SCW, then the separated solid phase product with concentrated metals was subjected to an acid leaching process for metals recovery. The effect of SCW pre-treatment on the recovery of different metals from waste PCBs was investigated. Two methods of SCW pre-treatment were studied: supercritical water oxidation (SCWO) and supercritical water depolymerization (SCWD). Experimental results indicated that SCWO and SCWD pre-treatment had significant effect on the recovery of different metals. SCWO pre-treatment was highly efficient for enhancing the recovery of $\mathrm{Cu}$ and $\mathrm{Pb}$, and the recovery efficiency increased significantly with increasing pre-treatment temperature. The recovery efficiency of $\mathrm{Cu}$ and $\mathrm{Pb}$ for SCWO pre-treatment at $420^{\circ} \mathrm{C}$ was $99.8 \%$ and $80 \%$, respectively, whereas most of the $\mathrm{Sn}$ and $\mathrm{Cr}$ were immobilized in the residue. The recovery of all studied metals was enhanced by SCWD pre-treatment and increased along with pre-treatment temperature. Up to $90 \%$ of $\mathrm{Sn}, \mathrm{Zn}, \mathrm{Cr}, \mathrm{Cd}$, and Mn could be recovered for SCWD pre-treatment at $440{ }^{\circ} \mathrm{C}$.
\end{abstract}

๑) 2013 Elsevier Ltd. All rights reserved.

\section{Introduction}

Printed circuit boards (PCBs) is the essential part of almost all waste electrical and electronic equipment (WEEE) as its production is the basis of the electronic industry (Li et al., 2007). In general, waste PCBs contains approximately $30 \%$ metals and $70 \%$ nonmetals (Huang et al., 2009). The typical metals in PCBs consist of $\mathrm{Cu}, \mathrm{Sn}$, $\mathrm{Pb}, \mathrm{Cd}, \mathrm{Cr}, \mathrm{Zn}, \mathrm{Ni}$, and $\mathrm{Mn}$. The nonmetal portions of PCBs consist of thermoplastic and thermosetting resins (such as brominated epoxy resins) which are intermingled very much and also have metals or other materials embedded inside (Guan et al., 2008). Therefore, recycling of waste PCBs is an important subject not only for the protection of environment but also for the recovery of valuable materials such as metals (Yazici et al., 2010).

Currently, metallurgical techniques, including pyrometallurgical process (Lee et al., 2007; Moltó et al., 2011) and hydrometallurgical process (Oishi et al., 2007; Jha et al., 2012; Tuncuk et al., 2012) are the two traditional approaches for the recovery of metals from waste PCBs. Hydrometallurgical processes with relatively low

\footnotetext{
* Corresponding author at: Department of Environment and Equipment Engineering, Fujian University of Technology, Fuzhou 350108, People's Republic of China. Tel.: +8659122863268.

E-mail address: xiu_chem@hotmail.com (F.-R. Xiu).
}

capital costs, no gas/dust formation, operational selectivity and suitability for small scale applications are propitious alternatives for the treatment of waste PCBs (Havlik et al., 2010; Pant et al., 2012; Tuncuk et al., 2012). In addition, many researchers have used various mechanical methods as pre-treatment to separate metals from PCBs, such as shape separation (Gungor and Gupta, 1998), jigging (Schmelzer and Wolf, 1996), density-based separation (Jirang and Forssberg, 2003), two-step crushing and corona electrostatic separation (Li et al., 2007). However, such processes not only can not remove toxic organic matters such as BFR in waste PCBs efficiently, but also have a considerable loss of valuable metal due to the insufficient liberation (Ogunniyi and Vermaak, 2007, 2009).

Recently, supercritical water (SCW) technique has been widely applied to the decomposition process of stable toxic organic wastes (O'Brien et al., 2005). At supercritical conditions $\left(T>374^{\circ} \mathrm{C}\right.$, $P>22.1 \mathrm{MPa}$ ), organic compounds and water form a single and homogeneous phase, which allows reaction to proceed rapidly by an elimination of the potential interface mass transport limitations (Modell, 1989; Shaw et al., 1991). At present, there are two main SCW processes used for the treatment of waste PCBs (Chien et al., 2000; Goto et al., 2003; Xiu and Zhang, 2009; Onwudili and Williams, 2009; Yin et al., 2011; Wang and Zhang, 2012). One is supercritical water oxidation (SCWO) process in the 
presence of oxygen, and the other is supercritical water depolymerization (SCWD) process under reducing atmosphere.

Chien et al. (2000) reported that toxic organic matters in waste PCBs could be degraded efficiently in SCWO process, and the formation of brominated polycyclic aromatic hydrocarbons (PAHs) was eliminated at the same time. More lately, the SCWO was used as a pre-treatment to decompose toxic organic matters of waste PCBs in our previous study (Xiu and Zhang, 2009, 2012). On the other hand, SCWD was widely applied to the recovery process of polymer materials in waste PCBs because SCW is an excellent hydrolysis reagent (Goto et al., 2003; Onwudili and Williams, 2009; Yin et al., 2011; Wang and Zhang, 2012). Polymers in waste PCBs could be monomerized by noncatalytic solvolysis in SCWD (Goto et al., 2006) and the reforming of SCWD is an efficient process for the removal of bromine atoms in brominated flame-retarded polymer (Onwudili and Williams, 2009; Yin et al., 2011). Hence, it is feasible and benign to decompose toxic organic matters, liberate and enrich the metals at the same time using SCWO and SCWD as pre-treatment techniques for subsequent hydrometallurgical process.

However, most of the above-mentioned reports focus on the reaction behavior of organic matters in waste PCBs during SCWO or SCWD treatment. Little is known about the distribution, speciation and valence variation of metals after SCW process. Particularly, it is still unclear how the SCW reaction conditions such as temperature, which is the most important influencing factor in SCW process, influence the recovery of metals in the treatment of waste PCBs.

In this study, we proposed an efficient and environmentally friendly process for metals recovery from waste PCBs by SCWO/ SCWD pre-treatment combined with acid leaching. In the proposed process, waste PCBs were pre-treated by SCW, then the separated solid phase product with concentrated metals was subjected to an acid leaching process for metals recovery. The effect of SCWO/ SCWD pre-treatment on the recovery of different metals from waste PCBs is discussed. The objectives of the present work are (1) to evaluate the effect of SCWO and SCWD pre-treatment on the physical and chemical characteristics of metals in waste PCBs, and (2) to investigate the differences between SCWO' effect and SCWD' effect on the recovery of different metals from waste PCBs. $\mathrm{Cu}, \mathrm{Sn}, \mathrm{Pb}, \mathrm{Cd}, \mathrm{Cr}, \mathrm{Zn}$, and $\mathrm{Mn}$ were selected as target elements, among which $\mathrm{Cu}$ is the richest metallic element (around 20\%) in waste PCBs, while $\mathrm{Sn}, \mathrm{Pb}, \mathrm{Cd}, \mathrm{Cr}, \mathrm{Zn}$, and $\mathrm{Mn}$ are of environmental and public health concern.

\section{Materials and methods}

\subsection{Materials}

Waste PCBs used in this work were mainly collected and disassembled from discarded telephones, PCs, and other electrical equipments. After the components (relays, capacitors, etc.) were disassembled, the PCBs were sent to comminute in a cutting mill until the particle size $<3 \mathrm{~mm}$. Metal content in the original PCBs was measured by ICP-OES (OPTIMA 2000, Perkin-Elmer) after digestion (Oishi et al., 2007). The analysis results are given in Table 1. All chemicals were purchased from Chemical Reagent Company of Beijing in analytical grade and all of them were used as received.

\subsection{SCWO and SCWD pre-treatments}

The reaction conditions of SCWO and SCWD pre-treatments are presented in Table 2. In every SCWO pre-treatment, $5 \mathrm{~g}$ of PCBs sample and $50 \mathrm{ml}$ of distilled water were employed, while $40 \mathrm{ml}$ of hydrogen peroxide $\left(\mathrm{H}_{2} \mathrm{O}_{2}, 30 \mathrm{wt}\right.$.\%) was used as oxygen source.
Table 1

Mass percent of metals in original waste PCBs and solid product obtained from SCWO and SCWD pre-treatment (wt.\%).

\begin{tabular}{lccc}
\hline Metal element & $C_{i}$ & SCWO & SCWD \\
\hline $\mathrm{Cu}$ & 18.19 & 27.8 & 25.5 \\
$\mathrm{Zn}$ & 3.20 & 4.72 & 4.5 \\
$\mathrm{Mn}$ & 0.60 & 0.39 & 0.84 \\
$\mathrm{Cr}$ & 0.29 & 0.43 & 0.41 \\
$\mathrm{Cd}$ & 0.18 & 0.27 & 0.25 \\
$\mathrm{Sn}$ & 5.10 & 7.6 & 7.16 \\
$\mathrm{~Pb}$ & 2.03 & 3.1 & 2.9 \\
\hline
\end{tabular}

$C_{i}$ : initial percentage composition of metals in waste PCBs.

Reaction time: $60 \mathrm{~min}$; reaction temperature: $420^{\circ} \mathrm{C}$.

Table 2

Conditions of SCWO and SCWD experiments ( $P_{i}$ : initial pressure; $P_{f}$ : final pressure).

\begin{tabular}{lllll}
\hline Experiment & Temperature $\left({ }^{\circ} \mathrm{C}\right)$ & Time $(\mathrm{min})$ & $P_{i}(\mathrm{MPa})$ & $P_{f}(\mathrm{MPa})$ \\
\hline SCWO 1 & 370 & 60 & 21 & 25 \\
SCWO 2 & 380 & 60 & 22 & 28 \\
SCWO 3 & 390 & 60 & 22 & 29 \\
SCWO 4 & 400 & 60 & 23 & 30 \\
SCWO 5 & 410 & 60 & 23 & 31 \\
SCWO 6 & 420 & 60 & 25 & 33 \\
SCWO 7 & 430 & 60 & 26 & 33 \\
SCWO 8 & 440 & 60 & 26 & 34 \\
SCWO 9 & 420 & 15 & 25 & 26 \\
SCWO 10 & 420 & 30 & 25 & 29 \\
SCWO 11 & 420 & 90 & 25 & 34 \\
SCWO 12 & 420 & 120 & 25 & 34 \\
SCWD 1 & 370 & 60 & 17 & 20 \\
SCWD 2 & 380 & 60 & 18 & 21 \\
SCWD 3 & 390 & 60 & 20 & 23 \\
SCWD 4 & 400 & 60 & 20 & 25 \\
SCWD 5 & 410 & 60 & 22 & 26 \\
SCWD 6 & 420 & 60 & 23 & 27 \\
SCWD 7 & 430 & 60 & 24 & 28 \\
SCWD 8 & 440 & 60 & 25 & 28 \\
SCWD 9 & 420 & 15 & 23 & 25 \\
SCWD 10 & 420 & 30 & 23 & 26 \\
SCWD 11 & 420 & 90 & 23 & 29 \\
SCWD 12 & 420 & 120 & 23 & 29 \\
\hline
\end{tabular}

$\mathrm{H}_{2} \mathrm{O}_{2}$ was decomposed and the released $\mathrm{O}_{2}$ was dissolved in supercritical water $\left(\mathrm{H}_{2} \mathrm{O}_{2}=\mathrm{H}_{2} \mathrm{O}+1 / 2 \mathrm{O}_{2}\right)$. Pre-treatment experiments were conducted in a 200-ml high-pressure reactor made of 316 alloy (WYF-2 from HUAAN, China). The reactor was heated to temperatures ranging from 370 to $440{ }^{\circ} \mathrm{C}$, and kept at these temperatures for selected residence time. The increase of temperature was at the rate of $10^{\circ} \mathrm{C}$ per minute. The reactions were carried out at the time range of $15-120 \mathrm{~min}$. The pressure inside was monitored by a pressure gauge attached to the reactor. The pressure in the reactor was changed during the reaction process and whose value depended upon the reaction conditions and the filling rate of the reactor. When the reactor was heated to selected temperature, the pressure at this point was defined as the initial pressure. After that, the reaction was held at this temperature for selected residence time. The pressure inside was defined as the final pressure when the residence time reached the selected value.

Three phases (solid, aqueous, and gas) were produced after reaction and metals could exist in the phases of solid and aqueous. After each SCWO pre-treatment, solid phase and aqueous phase were separated using a vacuum filter. Metal content in the aqueous phase of the SCWO-treated PCBs was measured by ICP-OES. The obtained solid residue was dried in an oven at $105^{\circ} \mathrm{C}$ overnight, then weighed and kept in a dryer for subsequent leaching experiments.

SCWD pre-treatments were carried out by using a 200-ml highpressure reactor made of 316 alloy which was the same as the one used in SCWO treatment. In order to acquire reducing atmosphere, 
air in the reactor was purged by argon gas for $3 \mathrm{~min}$ before the SCWD reaction. The details of SCWD reaction conditions are given in Table 2 and the operation steps are the same as the SCWO experiments.

Metal content in the SCWO/SCWO-treated PCBs was measured by ICP-OES after digestion (Oishi et al., 2007). The analysis results are given in Table 1 . The solid phase yield was calculated based on the weight of solid phase product after SCWO/SCWO pre-treatment and defined as follows:

Solid phase yield $(\%)=W_{1} \times 100 / W_{2}$

where $W_{1}$ is the weight of solid phase product after SCWO/SCWO pre-treatment, $W_{2}$ the initial weight of waste PCBs sample.

The metal distribution in solid phase product is defined as follows:

Metal distribution in solid phase product $(\%)=W_{3} \times 100 / W_{4}$

where $W_{3}$ is the metal weight in solid phase product separated from waste PCBs after SCWO, $W_{4}$ the initial metal weight of waste PCBs sample.

Organic matter weight of the initial PCBs was determined by the loss of ignition (LOI) at $550{ }^{\circ} \mathrm{C}$ for $1 \mathrm{~h}$. The carbon and hydrogen content of the solid samples was measured by an Elemental Analyzer (vario EL, Elementar Analysensysteme $\mathrm{GmbH}$ ). The $\mathrm{pH}$ of solutions was measured by a Radiometer Analytical pH electrode (PHS-3D, LEICI). The structure of the solid phase product of waste PCBs after SCWO/SCWD pre-treatment was characterized by Xray diffraction spectroscopy (XRD, Bruker D8 X-ray powder diffractometer) at $50 \mathrm{kV}$ and $100 \mathrm{~mA}$ using $\mathrm{Cu} \mathrm{K} \alpha$ radiation $(\lambda=1.5418 \AA$ ).

\subsection{Leaching experiments}

The PCBs samples without and after SCW treatment were introduced into a conical flask, then dilute $\mathrm{HCl}$ solution $(1 \mathrm{~mol} / \mathrm{l})$ was added. The volume of leaching reagent was $100 \mathrm{ml}$ and the weight of each sample was $1 \mathrm{~g}$. Flask was kept in constant stirring (300 rpm) with magnetic stirrer (SH-3 from JBD, Beijing, China) at $60^{\circ} \mathrm{C}$. The leaching time was controlled at $80 \mathrm{~min}$. After the leaching experiment, the filtrate was separated by centrifugation immediately and the metal content in the filtrate was measured by ICP-OES. The metal leaching efficiency is defined as follows:

Metal leaching efficiency $(\%)=W_{5} \times 100 / W_{6}$

where $W_{5}$ is the metal mass leached, $W_{6}$ the initial metal mass of SCW-treated PCBs sample.

\section{Results and discussion}

\subsection{Effect of SCWO and SCWD on the crystalline phases of waste PCBS}

To understand the influence of SCW treatment on metal change inside waste PCBs, X-ray powder diffraction examinations of SCWO-treated and SCWD-treated PCBs were performed. The SCW reaction temperature was controlled at 370, 380, 390, 400, $410,420,430$, and $440{ }^{\circ} \mathrm{C}$, respectively. The XRD analytical results of SCWO-treated samples are shown in Fig. 1. Cu, CuSn, and $\mathrm{SnO}_{2}$ were the main crystalline phases in the SCWO-treated PCBs residue at temperature $<400^{\circ} \mathrm{C}$. With increasing reaction temperature, $\mathrm{Cu}$ was oxidized to its oxidates $\left(400^{\circ} \mathrm{C}\right)$, and $\mathrm{CuO}$ and $\mathrm{Cu}_{2} \mathrm{O}$ became the main crystalline phases at temperature of 420 and $440{ }^{\circ} \mathrm{C}$. The variation of main crystalline phases provides a convenient way to follow the reaction of metallic element during SCWO process. It can be concluded that $\mathrm{Cu}$ element was inclined to form alloy substance with $\mathrm{Sn}$ at lower temperature stage of SCWO, and copper oxides such as $\mathrm{CuO}$ and $\mathrm{Cu}_{2} \mathrm{O}$ began to form

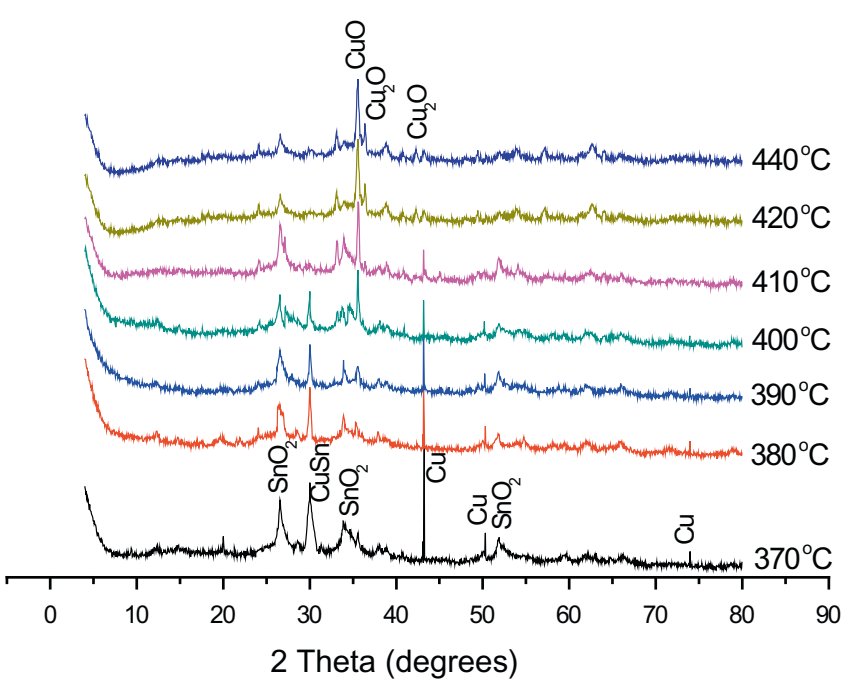

Fig. 1. X-ray diffraction patterns of the solid phase product from SCWO-treated PCBs.

at higher temperature, meanwhile, the copper alloy phase compounds decreased. Inversely, a considerable part of the Sn element could be efficiently oxidized to $\mathrm{SnO}_{2}$ at low temperature stage, even at $370{ }^{\circ} \mathrm{C}$.

However, SCWD-treated PCBs samples show quite similar XRD patterns (the patterns are not showed here) compared to the one without SCW treatment. The main crystalline phases in the SCWD-treated PCBs at different temperatures were metallic copper.

\subsection{Effect of SCWO and SCWD on solid phase yield}

The effect of SCW pre-treatment conditions (reaction temperature and time) on solid phase yield is shown in Fig. 2. The results show that both the solid phase yields of samples treated by SCWO and SCWD decrease with the increase of temperature and time. At the same reaction temperature or time, the weight loss of sample treated by SCWO was much higher than the one treated by SCWD, indicating that the decomposition rate of organic matters during SCWO process was higher than that during SCWD process. The organic matters in waste PCBs are mainly plastics. Organic matter weight of the initial PCBs was determined by the loss of ignition (LOI) at $550{ }^{\circ} \mathrm{C}$ for $1 \mathrm{~h}$ (Havlik et al., 2010), and the weight percentage of organic matter in waste PCBs was $35.5 \%$. In addition, the solid phase yield of SCWO-treated sample reached a steady level after $400^{\circ} \mathrm{C}$ and $60 \mathrm{~min}$, while it needed higher temperature $\left(420^{\circ} \mathrm{C}\right)$ for the SCWD-treated one.

The enhancement of polymer decomposition in SCW was considered to be due to enhanced dissolving capacity of polymer in SCW and diffusion of water into the molten polymer phase (Goto et al., 2003). In the case of SCWO reaction, the decomposition of polymers could also be improved under the oxidation atmosphere due to the combinational effect of hydrolysis and oxidation. It was reported that polymer matters such as plastics were oxidized to $\mathrm{CO}_{2}$ and $\mathrm{H}_{2} \mathrm{O}$ very effectively in SCWO system (Chien et al., 2000; Hirth et al., 1996). Polymers with high molecular weight were decomposed into low molecular weight compounds along with SCWO process. The produced low molecular weight compounds become completely soluble in SCW, and organic compounds, oxygen, and water form a single and homogeneous phase, which allows the oxidation of low molecular weight organic compounds to proceed rapidly by an elimination of the potential interface mass transport limitations (Chien et al., 2000). However, hydrolysis is 

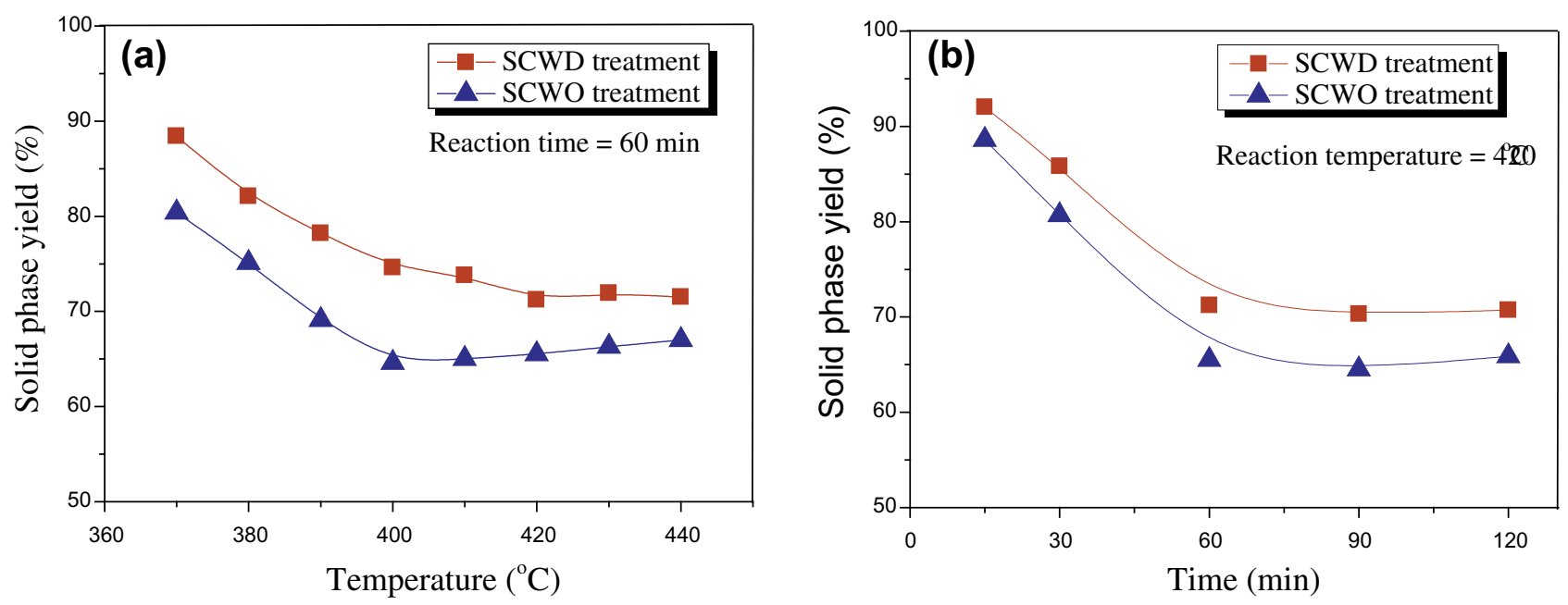

Fig. 2. Effect of SCW temperature (a) and time (b) on solid phase yield after pre-treatment.

supposed to be the most main reaction during the SCWD process. Polymers with high molecular weight were gradually depolymerized into low molecular weight compounds in SCWD process and its decomposition efficiency was lower when compared to SCWO treatment.

On the other hand, the pressure of SCW system may have a significant effect on the reactivity of organic matters. According to previous studies (Xiu and Zhang, 2010; Bo et al., 2009), supercritical fluid such as methanol or water is strong enough to destroy the solid particles and produce some porous structure in the solid waste particle due to the high pressure environment in SCW process. As a result, the porous structure are supposed to be positive for the diffusing of gas and liquid offspring produced inside the waste PCBs during the SCW process and accelerating the reaction of oxidation or depolymerization. Furthermore, the porous structure produced in SCW process also is positive for enhancing the leaching activity of metals liberated from the waste PCBs particles in subsequent leaching process.

The initial and final pressure of SCWO and SCWD experiments are shown in Table 2. The pressure, especially the final pressure, of SCWO system was distinctly higher than that of SCWD system at the same reaction temperature and time. In the initial stage of SCWO process, $\mathrm{H}_{2} \mathrm{O}_{2}$ was decomposed and the released $\mathrm{O}_{2}$ was dissolved in supercritical water, which resulted in a higher initial pressure. The pressure in the system continuously increased with increasing reaction temperature. Furthermore, the rapid oxidation of organic matters also led to the increase of pressure in system due to that a large amount of $\mathrm{CO}_{2}$ and $\mathrm{H}_{2} \mathrm{O}$ were produced during the SCWO process. However, the gas products derived from the depolymerization of polymer materials in SCWD system increased slowly because of the reaction rate of hydrolysis was slower than that of oxidation in SCWO process. The yield of gas products in SCWD process also was far below that of SCWO system, because a large portion of polymer matters were degraded into oil phase products of low molecular weight in SCWD process, while all of the polymer could be completely oxidized to $\mathrm{CO}_{2}$ and $\mathrm{H}_{2} \mathrm{O}$ in SCWO process.

In addition, it can be found in Fig. 2 that the solid phase yields increase somewhat when reaction temperature $>400^{\circ} \mathrm{C}$ or reaction time $>90$ min in SCWO process, which could be attributed to the fact that the oxidation of metal components led to the slight increase of the solid residue weight at this reaction stage. The results were consistent with the XRD analysis of the solid residue from SCWO-treated PCBs.

\subsection{Effect of SCWO and SCWD on distributions of metals in solid- aqueous phase products}

Some metals may be converted from insoluble to soluble species during the SCWO process because of the oxidizing atmosphere. To understand the migration characteristics of metals in solid-aqueous phase products during SCWO pre-treatment, the effect of SCWO temperature and time on metals distributions in solid phase products after pre-treatment was examined. The results are shown in Fig. 3a and $b$, respectively. When the temperature $<400^{\circ} \mathrm{C}$, the metals distributions in solid phase product except for $\mathrm{Mn}$ were near to $100 \%$ and the effect of temperature on the distributions was negligible (Fig. 3a). However, the metals distributions in solid phase product decreased slightly after $400{ }^{\circ} \mathrm{C}$, indicating that some insoluble species were converted to soluble species and dissolved in aqueous phase. The reason was that when reaction temperature $>400{ }^{\circ} \mathrm{C}$, most of the organic matters in waste PCBs were oxidized to $\mathrm{H}_{2} \mathrm{O}$ and $\mathrm{CO}_{2}$, which led to a decline of system $\mathrm{pH}$ and the increase of the dissolution of metal oxides produced in SCWO process. The system $\mathrm{pH}$ for SCWO pre-treatment at $370,380,390,400,410,420,430$, and $440{ }^{\circ} \mathrm{C}$ was $6.9,6.8,6.6$, $6.3,6.1,5.9,5.8$, and 5.8 , respectively.

The results of Mn element distribution after SCWO process were interesting. The distribution of $\mathrm{Mn}$ in solid phase product after SCWO pre-treatment decreased significantly with increasing the reaction temperature (Fig. 3a). Around $60 \%$ of $\mathrm{Mn}$ dissolved in aqueous phase after SCWO treatment when the reaction temperature $>440{ }^{\circ} \mathrm{C}$, indicating that considerable Mn element was transformed into water-soluble species such as manganate during the SCWO process. The remainder of $\mathrm{Mn}$ in solid phase product after SCWO pre-treatment could exist mainly as oxides with low valence state such as $\mathrm{MnO}_{2}$ and $\mathrm{Mn}_{2} \mathrm{O}_{3}$.

The effect of SCWO treatment time on metals distributions in solid phase products after SCWO pre-treatment is presented in Fig. 3b. The metals (except for $\mathrm{Mn}$ ) distributions in solid phase products were near to $100 \%$ and the effect of reaction time was negligible for all of the metals.

Because the composition of SCWD-treated PCBs mainly was zero-valent metals, all of the metal could remain in the solid phase product. In fact, metals such as $\mathrm{Cu}, \mathrm{Sn}, \mathrm{Pb}, \mathrm{Cd}, \mathrm{Cr}, \mathrm{Zn}$, and Mn could not be determined in the aqueous phase after SCWD reaction according to ICP analysis.

To further investigate the enrichment function of SCWO and SCWD process over the metals in waste PCBs, the mass percents 

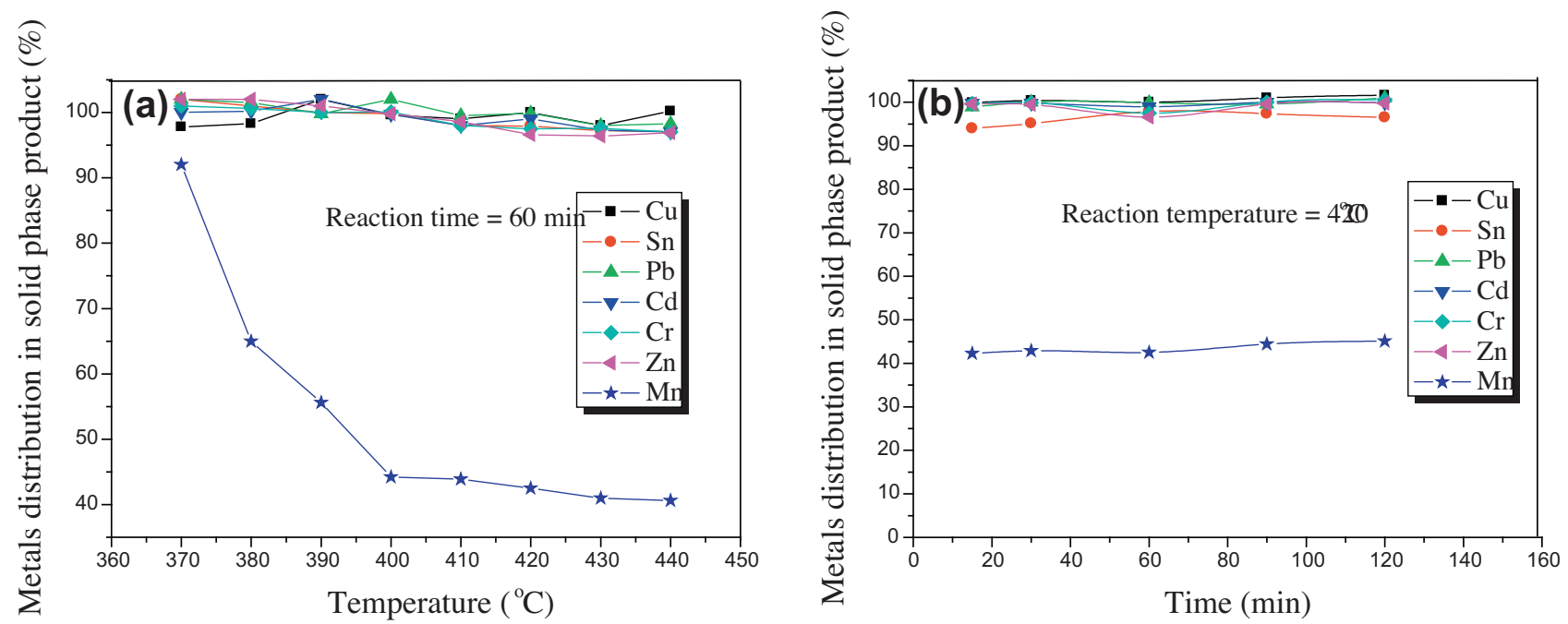

Fig. 3. Effects of SCWO temperature (a) and time (b) on metals distributions in solid phase product after pre-treatment.

Table 3

Content of carbon and hydrogen in solid phase products after SCWD pre-treatment.

\begin{tabular}{lcll}
\hline Sample & $\mathrm{C}(\%)$ & $\mathrm{H}(\%)$ & $\mathrm{H} / \mathrm{C}$ \\
\hline Original PCBs & 22.75 & 2.52 & 0.11 \\
SCWD-treated PCBs & 6.2 & 0.32 & 0.052 \\
\hline
\end{tabular}

SCWD reaction condition: $420^{\circ} \mathrm{C}, 60 \mathrm{~min}$.

of metals in solid product obtained from SCWO and SCWD process were determined (Table 1). The metals studied were concentrated effectively after SCWO and SCWD pre-treatment. Cu was the largest fraction present in all of the solid products obtained from different reaction temperature after SCWO and SCWD pretreatment. For example $\mathrm{Cu}$ content in solid product increased from $18.19 \%$ (the initial $\mathrm{Cu}$ content in waste PCBs) to $27.8 \%$ and $25.5 \%$ when the reaction temperature of $420^{\circ} \mathrm{C}$ was used in the SCWO and SCWD process, respectively. It also can be found that the enrichment function of SCWO was higher than that of SCWD process, which can be attributed to that part of organic matters are retained in the solid phase product of waste PCBs after SCWD pretreatment. The content of carbon and hydrogen in the solid phase product after SCWD pre-treatment at $420^{\circ} \mathrm{C}$ and $60 \mathrm{~min}$ is presented in Table 3. It can be found that the ratio of $\mathrm{H}$ to $\mathrm{C}$ decreased when compared to that of original PCBs sample, indicating that part of polymer matters was carbonated during the SCWD process. Also, part of carbon still existed as organic carbon in the solid phase product after SCWD pre-treatment due to that the solid phase product still contained a certain amount of hydrogen. Hence, we could deduce that both the two form of carbon (elemental carbon and organic carbon) existed in the solid phase product after SCWD pre-treatment. Goto et al. (2003) have also reported that a considerable part of polymer materials can be carbonated in SCWD process.

\subsection{Effect of SCWO on leaching efficiency of metals in leaching process}

Fig. 4 shows the kinetic curves of metals leaching from waste PCBs samples without SCW treatment in $1 \mathrm{M} \mathrm{HCl}$ at $60^{\circ} \mathrm{C}$. The leaching efficiencies of $\mathrm{Cu}$ and $\mathrm{Pb}$ in original PCBs samples was far lower than that of $\mathrm{Sn}, \mathrm{Cd}, \mathrm{Cr}, \mathrm{Zn}$, and $\mathrm{Mn}$. Cu is leached significantly only in the oxidative environment. There should be no significant reactions between $\mathrm{Cu}$ and $\mathrm{HCl}$ due to that $\mathrm{HCl}$ is a non-oxidizing acid. The reaction between $\mathrm{Pb}$ and $\mathrm{HCl}$ produces insoluble $\mathrm{PbCl}_{2}$, which can cover

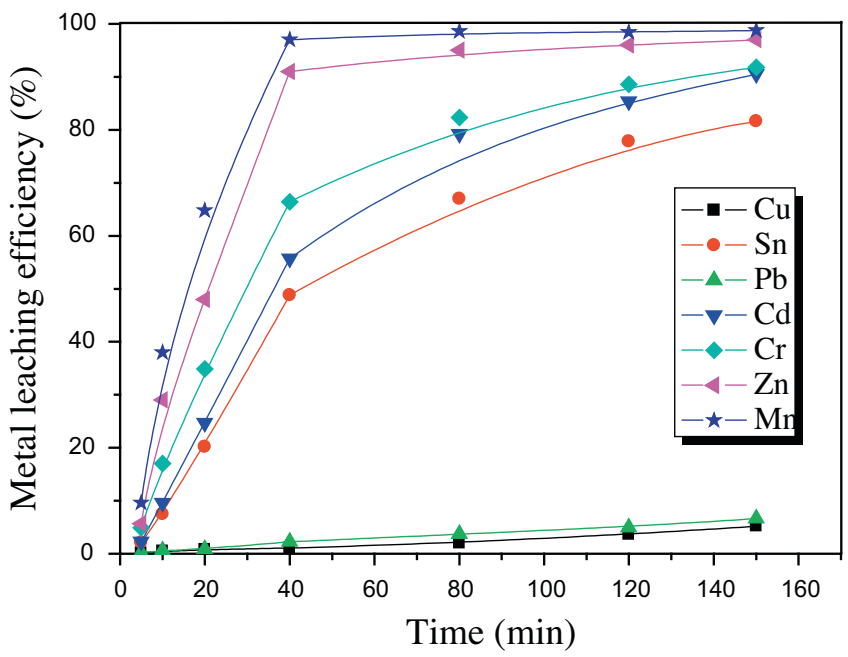

Fig. 4. Kinetic curves of metals leaching from waste PCBs samples without SCW treatment.

on the surface of $\mathrm{Pb}$ and lead to reduction in the overall rate of dissolution of $\mathrm{Pb}$. Unlike $\mathrm{Cu}$ and $\mathrm{Pb}$, metals such as $\mathrm{Sn}, \mathrm{Cd}, \mathrm{Cr}, \mathrm{Zn}$, and $\mathrm{Mn}$ are leached in $\mathrm{HCl}$ according to:

$\mathrm{M}+2 \mathrm{HCl}(\mathrm{aq})=\mathrm{MCl}_{2}+\mathrm{H}_{2}(\mathrm{~g})(\mathrm{M}=\mathrm{Sn}, \mathrm{Cd}, \mathrm{Cr}, \mathrm{Zn}$, and $\mathrm{Mn})$

The effect of SCWO temperature on the metals leaching in $\mathrm{HCl}$ solution is shown in Fig. 5. The leaching efficiency of $\mathrm{Cu}$ and $\mathrm{Pb}$ increased significantly with increasing the reaction temperature of SCWO, and reached a stable level after $420^{\circ} \mathrm{C}$. The leaching efficiency of $\mathrm{Cu}$ and $\mathrm{Pb}$ after SCWO pre-treatment at $420^{\circ} \mathrm{C}$ was $99.8 \%$ and $80 \%$, respectively. $\mathrm{Cu}$ and $\mathrm{Pb}$ were supposed to be gradually oxidized to their oxides during the SCWO treatment, and the oxidation reaction was more completely at higher temperature. The oxides of $\mathrm{Cu}$, as opposed to metallic $\mathrm{Cu}$ in original PCBs samples, are well leached in hydrochloric acid. Leaching solution was concentrated to crystallize $\mathrm{CuCl}_{2} \cdot 2 \mathrm{H}_{2} \mathrm{O}$, and the grade of crystal $\mathrm{CuCl}_{2} \cdot 2 \mathrm{H}_{2} \mathrm{O}$ reached $98.5 \%$.

The influence of SCWO treatment on the leaching of $\mathrm{Zn}, \mathrm{Cd}$, and Mn was insignificant. The leaching efficiency of $\mathrm{Zn}, \mathrm{Cd}$, and $\mathrm{Mn}$ exceeded 95\%, which was similar to the results of the original PCBs samples. The reason is that the difference of the leaching activity 


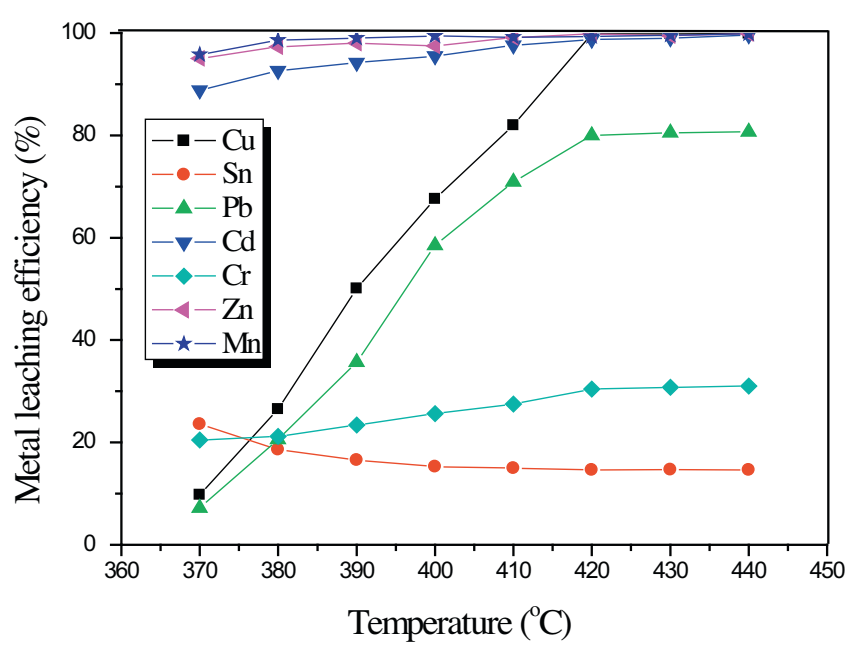

Fig. 5. Effect of SCWO temperature on metals leaching from SCWO-treated PCBs samples. (SCWO reaction time: $60 \mathrm{~min}$; leaching time: $80 \mathrm{~min}$ ).

between $\mathrm{Zn}, \mathrm{Cd}, \mathrm{Mn}$ and their oxides is negligible. Inversely, the leaching efficiency of Sn in SCWO-treated PCBs was around 15\%, which was far below that of original PCBs samples.

In the SCWO process, the Sn was oxidized to $\mathrm{SnO}_{2}$ quickly even at the low temperature stage (Fig. 1). It is well know that metallic $\mathrm{Sn}$ can be leached in $\mathrm{HCl}$, but $\mathrm{Sn}$ oxides are not leached in $\mathrm{HCl}$ as the value of change $\Delta G^{\circ}$ of the reaction between $\mathrm{SnO}_{2}$ and $\mathrm{HCl}$ is $220.43 \mathrm{~kJ} / \mathrm{mol}$.

$\mathrm{SnO}_{2}+4 \mathrm{HCl}(\mathrm{aq})=\mathrm{SnCl}_{2}+2 \mathrm{H}_{2} \mathrm{O}+\mathrm{Cl}_{2}(\mathrm{~g}) \quad \Delta G_{60}^{\circ}=220.43 \mathrm{~kJ} / \mathrm{mol}$

It also can be found in Fig. 5 that the leaching efficiency of Sn slightly decreased with the increase of SCWO temperature, which may be attributed to that part of Sn still remained in the metallic form at low temperature stage of SCWO treatment and was leached consequently. Another possible reason is that part of Sn was oxidized to $\mathrm{SnO}$, which could be leached easily compared to $\mathrm{SnO}_{2}$, at low temperature stage of SCWO.

$\mathrm{SnO}+2 \mathrm{HCl}(\mathrm{aq})=\mathrm{SnCl}_{2}(\mathrm{aq})+\mathrm{H}_{2} \mathrm{O} \quad \Delta G_{60}^{\circ}=-71.684 \mathrm{~kJ} / \mathrm{mol}$

Like Sn, the leaching efficiency of $\mathrm{Cr}$ in SCWO-treated PCBs was far below that of original PCBs samples, and no significant effect of SCWO temperature can be found on the leaching of $\mathrm{Cr}$. In the SCWO process, $\mathrm{Cr}$ could be oxidized to $\mathrm{CrO}_{3}, \alpha-\mathrm{HCrO}_{2}$, or $\mathrm{Cr}_{2} \mathrm{O}_{3}$ (Veriansyah et al., 2007). However, the chemical property of $\mathrm{Cr}$ and their oxides was quite different from each other. It is easy for metallic $\mathrm{Cr}$ to react with dilute $\mathrm{HCl}$ and release $\mathrm{H}_{2} \cdot \mathrm{CrO}_{3}$ can dissolve in water to produce $\mathrm{H}_{2} \mathrm{CrO}_{4}$. However, there is no significant reaction between $\alpha-\mathrm{HCrO}_{2} / \mathrm{Cr}_{2} \mathrm{O}_{3}$ and dilute $\mathrm{HCl}$ because the alkalinity of $\alpha-\mathrm{HCrO}_{2} / \mathrm{Cr}_{2} \mathrm{O}_{3}$ is very weak. If $\mathrm{Cr}$ was oxidized to $\mathrm{CrO}_{3}$ in SCWO process, a large portion of $\mathrm{Cr}$ should transfer into aqueous phase after SCWO reaction because of the formation of $\mathrm{H}_{2} \mathrm{CrO}_{4}$, but the recovery yield of $\mathrm{Cr}$ in solid residue after SCWO treatment was close to $100 \%$ (Fig. 3). Hence, $\mathrm{Cr}$ is supposed to be oxidized to insoluble species such as $\alpha-\mathrm{HCrO}_{2}$ and $\mathrm{Cr}_{2} \mathrm{O}_{3}$ during the SCWO process.

\subsection{Effect of SCWD on metals leaching efficiency in leaching process}

By comparing Figs. 4 and 6, it can be found that the leaching efficiencies of nearly all metals in SCWD-treated PCBs were higher than that of original samples at the same leaching conditions (temperature and time), indicating that the liberation of metals from waste PCBs could be enhanced by SCWD treatment and result in

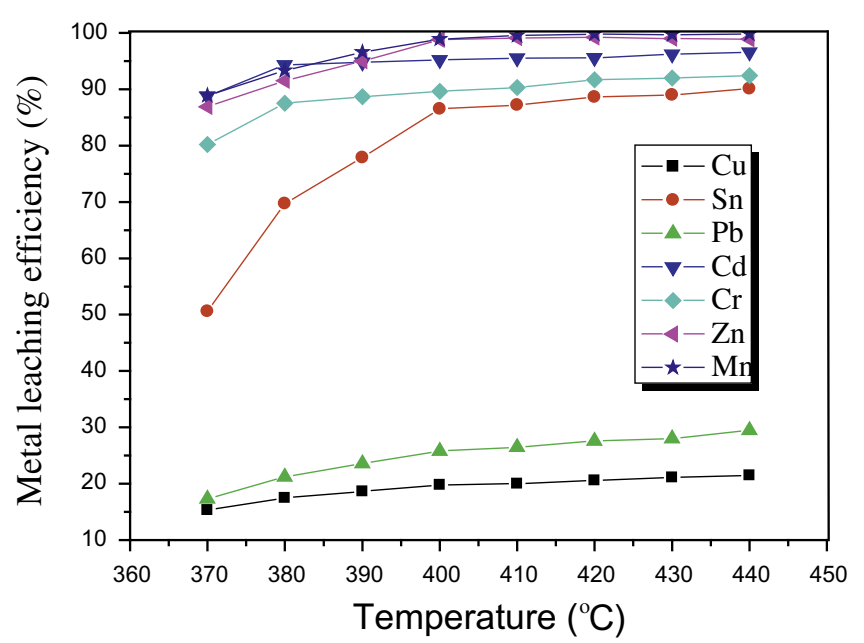

Fig. 6. Effect of SCWD temperature on metals leaching from SCWD-treated PCBS samples. (SCWD reaction time: $60 \mathrm{~min}$; leaching time: $80 \mathrm{~min}$ ).

the increase of the reaction surface of metals, which had a positive influence on the extraction of metals in subsequent hydrometallurgical leaching process. However, the leaching efficiencies of Sn, Zn, and Mn were lower than that of original samples when the SCWD treatment temperature $<380^{\circ} \mathrm{C}$. It seems that some alloy phases of $\mathrm{Sn}, \mathrm{Zn}$, and $\mathrm{Mn}$ were inclined to be formed at low temperature stage of SCWD and the formed metal alloy could lower the leaching activity of metals in the subsequent leaching process.

The effect of SCWD treatment at different temperature on the metals leaching from waste PCBs in subsequent leaching process is given in Fig. 6. The leaching efficiencies of $\mathrm{Sn}, \mathrm{Cd}, \mathrm{Cr}, \mathrm{Zn}$, and Mn increased with increasing the SCWD temperature, especially the leaching of Sn rose from $50.6 \%$ to $90.1 \%$ with the increase of reaction temperature from $370^{\circ} \mathrm{C}$ to $440{ }^{\circ} \mathrm{C}$. PCBs are a heterogeneous mixture of glass fiber, resin and multiple kinds of metal. In the SCWD process, polymer matters in waste PCBs could be gradually decomposed into compounds of lower molecular weight, and the liberation degree of metals increased with the increase of reaction temperature.

In addition, according to our previous studies (Zhang and Itoh, 2006; Bo et al., 2009; Xiu and Zhang, 2010), supercritical fluid such as water and methanol is strong enough to destroy the solid particles such as fly ash or waste PCBs particles. An increasing number of porous structures can be produced in the solid waste particle as the reaction temperature rise during the SCWD process. As a result, SCW molecules probably can diffuse into the waste PCBs particle through the porous structure and eventually create big holes in the particle. The holes in the particle are supposed to be positive for the diffusing and leaching of metals from the inside of waste PCBs during the subsequent leaching process.

However, the effect of SCWD temperature on the leaching of $\mathrm{Cu}$ and $\mathrm{Pb}$ in subsequent leaching process was negligible. With the increase of temperature in SCWD process, the leaching of $\mathrm{Cu}$ and $\mathrm{Pb}$ can be enhanced by increasing the reaction surface and porous structure, however, the metal alloy formed during such process may have a negative influence on subsequent leaching process.

\section{Conclusions}

In this work, an efficient and environmentally friendly pretreatment for metals recovery from waste PCBs was proposed. The experimental results showed that SCWO/SCWD pre-treatment technology was a promising method for organic matters decomposition and metals enrichment in the treatment of waste PCBs. 
In the SCWO process, a considerable part of Sn could be efficiently oxidized to $\mathrm{SnO}_{2}$ at low temperature, while $\mathrm{Cu}$ was inclined to form alloy substances with $\mathrm{Sn}$ at lower temperature and copper oxides were formed at higher temperature. The main crystalline phases in the SCWD-treated PCBs at different temperature were metallic copper. The decomposition efficiency of organic matters in waste PCBs in SCWD pre-treatment was lower than that in SCWO process under the same reaction condition. The enrichment function of SCWO and SCWD process for metals in waste PCBs was prominent. The distributions of metals (except for $\mathrm{Mn}$ ) in solid phase product after SCWO process were near 100\% and the effect of reaction temperature on the metals distribution was negligible. Approximately $60 \%$ of Mn dissolved in aqueous phase after SCWO treatment when the reaction temperature $>420{ }^{\circ} \mathrm{C}$ due to that considerable Mn element was transformed into water-soluble species during the SCWO process. All the metals studied remained in the solid phase product after SCWD pre-treatment because the composition of SCWD-treated PCBs mainly was zero-valent metals.

SCWO had a significant enhancement effect on the recovery of $\mathrm{Cu}$ and $\mathrm{Pb}$. Hence, it is a promising pre-treatment not only for the detoxification of BFR and $\mathrm{Pb}$ in waste PCBs, but also for the recovery of Cu resource. However, SCWO was not suitable for Sn and $\mathrm{Cr}$ recovery due to the immobilization function of SCWO. SCWD pre-treatment was suitable for improving the recovery of $\mathrm{Sn}, \mathrm{Cd}, \mathrm{Cr}, \mathrm{Zn}$, and $\mathrm{Mn}$, whereas its enhancement effect on $\mathrm{Cu}$ and $\mathrm{Pb}$ was not satisfying. The further studies of this work such as the recovery of precious metals from waste PCBs after SCWO/ SCWD pre-treatment are in progress.

\section{Acknowledgements}

This research was financially supported by the National Natural Science Foundation of China (21077120), the Natural Science Foundation of Fujian Province (2011J05016), the Foundation of Fujian Educational Committee (JA11177), the Special Science Funding of Provincial Universities of Fujian (JK2012032), and the Opening Project of Key Laboratory of Solid Waste Treatment and Resource Recycle (SWUST), Ministry of Education of China (11zxgk06).

\section{References}

Bo, D., Zhang, F.-S., Zhao, L., 2009. Influence of supercritical water treatment on heavy metals in medical waste incinerator fly ash. Journal of Hazardous Materials 170, 66-71.

Chien, Y.-C., Wang, H.P., Lin, K.-S., Yang, Y.W., 2000. Oxidation of printed circuit board wastes in supercritical water. Water Research 34, 4279-4283.

Goto, M., Kitamura, M., Hirose, T., Shibata, K., 2003. Depolymerization of printed circuit board in near-critical water. Hydrothermal Reactions and Techniques. World Scientific, New Jersey, pp. 201-208.

Goto, M., Sasaki, M., Hirose, T., 2006. Reactions of polymers in supercritical fluids for chemical recycling of waste plastics. Journal of Materials Science 41, 15091515.

Guan, J., Li, Y.S., Lu, M.X., 2008. Product characterization of waste printed circuit board by pyrolysis. Journal Analytical Applied Pyrolysis 83, 185-189.

Gungor, A., Gupta, S.M., 1998. Disassembly sequence planning for products with defective parts in product recovery. Computers \& Industrial Engineering 35, 161-164.

Havlik, T., Orac, D., Petranikova, M., Miskufova, A., Kukurugya, F., Takacova, Z., 2010 Leaching of copper and tin from used printed circuit boards after thermal treatment. Journal of Hazardous Materials 183, 866-873.
Hirth, Th., Schweppe, R., Jahnke, S., Bunte, G., Eisenreich, N., Krause, H., 1996. Degradation process in sub- and supercritical water. Process Technology Proceedings 12, 163-168.

Huang, K., Guo, J., Xu, Z., 2009. Recycling of waste printed circuit boards: A review of current technologies and treatment status in China. Journal of Hazardous Materials 164, 399-408.

Jha, M.K., Kumari, A., Choubey, P.K., Lee, J., Kumar, V., Jeong, J., 2012. Leaching of lead from solder material of waste printed circuit boards (PCBs). Hydrometallurgy 121-124, 28-34.

Jirang, C., Forssberg, E., 2003. Mechanical recycling of waste electric and electronic equipment: a review. Journal of Hazardous Materials 99, 243-263.

Lee, J.-C., Song, H.T., Yoo, J.-M., 2007. Present status of the recycling of waste electrical and electronic equipment in Korea. Resources Conservation and Recycling 50, 380-397.

Li, J., Lu, H.Z., Guo, J., Xu, Z.M., Zhou, Y.H., 2007. Recycle technology for recovering resources and products from waste printed circuit boards. Environmental Science and Technology 41, 1995-2000.

Modell, M., 1989. In Standard Handbook of Hazardous Waste Treatment and Disposal. McGraw-Hill, New York.

Moltó, J., Egea, S., Conesa, J.A., Font, R., 2011. Thermal decomposition of electronic wastes: Mobile phone case and other parts. Waste Management 31, 2546-2552.

O'Brien, C.P., Thies, M.C., Bruce, D.A., 2005. Supercritical water oxidation of the PCB congener 2-chlorobiphenyl in methanol solutions: a kinetic analysis. Environmental Science and Technology 39, 6839-6844.

Ogunniyi, I.O., Vermaak, M.K.G., 2007. Improving printed circuit board physical processing-an overview. In: Proceedings of European Metallurgical Conference, Dusseldorf, Germany, pp. 1645-1656.

Ogunniyi, I.O., Vermaak, M.K.G., 2009. Investigation of froth flotation for beneficiation of printed circuit board comminution fines. Minerals Engineering 22 (4), 378-385.

Oishi, T., Koyama, K., Alam, S., 2007. Recovery of high purity copper cathode from printed circuit boards using ammoniacal sulfate or chloride solutions. Hydrometallurgy 89, 82-88.

Onwudili, J.A., Williams, P.T., 2009. Degradation of brominated flame-retarded plastics (Br-ABS and Br-HIPS) in supercritical water. Journal Supercritical Fluids 49, 356-368.

Pant, D., Joshi, D., Upreti, M.K., Kotnala, R.K., 2012. Chemical and biological extraction of metals present in E waste: A hybrid technology. Waste Management 32, 979-990.

Schmelzer, S.G., Wolf, H., 1996. New wet treatment for components of incineration slag. Aufbereiten -Technol 37, 149-157.

Shaw, R.W., Brill, T.B., Clifford, A.A., 1991. Supercritical water. A medium for chemistry. Chemical \& Engineering News 69, 26-39.

Tuncuk, A., Stazi, V., Akcil, A., Yazici, E.Y., Deveci, H., 2012. Aqueous metal recovery techniques from E-scrap: hydrometallurgy in recycling. Minerals Engineering $25,28-37$.

Veriansyah, B., Kim, J.-D., Lee, Y.-W., 2007. Simultaneous recovery of chromium and destruction of organics from LCD manufacturing process wastewater by supercritical water oxidation. Journal of Cleaner Production 15, 972-978.

Wang, Y., Zhang, F.-S., 2012. Degradation of brominated flame retardant in computer housing plastic by supercritical fluids. Journal of Hazardous Materials 205-206, 156-163.

Xiu, F.-R., Zhang, F.-S., 2009. Preparation of nano- $\mathrm{Cu}_{2} \mathrm{O} / \mathrm{TiO}_{2}$ photocatalyst from waste printed circuit boards by electrokinetic process. Journal of Hazardous Materials 172, 1458-1463.

Xiu, F.-R., Zhang, F.-S., 2010. Materials recovery from waste printed circuit boards by supercritical methanol. Journal of Hazardous Materials 178, 628-634.

Xiu, F.-R., Zhang, F.-S., 2012. Size-controlled preparation of $\mathrm{Cu}_{2} \mathrm{O}$ nanoparticles from waste printed circuit boards by supercritical water combined with electrokinetic process. Journal of Hazardous Materials 233-234, 200-206.

Yazici, E., Deveci, H., Alp, I., Akçil, A., Yazici, R., 2010. Characterisation of computer printed circuit boards for hazardous properties and beneficiation studies. XXV. IMPC, Brisbane, Australia, 6-10 September, pp. 4009-4015.

Yin, J., Li, G.M., He, W.Z., Huang, J.W., Xu, M., 2011. Hydrothermal decomposition of brominated expoxy resin in waste printed circuit boards. Journal of Analytical and Applied Pyrolysis 92, 131-136.

Zhang, F.-S., Itoh, H., 2006. A novel process utilizing subcritical water and nitrilotriacetic acid to extract hazardous elements from MSW incinerator fly ash. Science of the Total Environment 369, 273-279. 